\title{
Determinação do tempo térmico para o desenvolvimento de mudas de eucalipto na fase de enraizamento
}

\author{
Aline S. de 0 liveira $^{1}$, Antonio J. Steidle $\mathrm{Neto}^{2}$, Aristides Ribeiro ${ }^{1}$, \\ Nilton Jr. L. Rascon ${ }^{3}$, Yhasmin P. Rody ${ }^{1} \&$ André Q. de Almeida ${ }^{4}$
}

\begin{abstract}
RESU M 0
O gênero Eucalyptus possui destaque em plantios florestais comerciais em virtude de apresentar crescimento rápido e ser adaptado às condições climáticas do Brasil. Dentre as fases de maior importância para produção de mudas de eucalipto via propagação vegetativa, destaca-se a de enraizamento em razão das exigências hídricas, nutricionais e de manejo, passíveis de comprometer a qualidade das mudas na crescente demanda silvicultural brasileira. Realizou-se esta pesquisa objetivando-se determinar a soma térmica para o enraizamento de estacas clonais de eucalipto (Eucalyptus grandis x E. urophylla) e gerar equações de estimativa para o acúmulo de biomassa na mesma fase de produção, com base no conceito de graus-dia (tempo térmico). 0 trabalho foi conduzido em casa de vegetação climatizada no viveiro de pesquisas do Departamento de Engenharia Florestal, da Universidade Federal de Viçosa, Minas G erais. No início do enraizamento a média da biomassa fresca das mudas foi de $0,76 \pm 0,17 \mathrm{~g}$ e da biomassa seca de $0,17 \pm 0,04 \mathrm{~g}$. Ao final do enraizamento a média da biomassa fresca e seca das mudas foi de $1,49 \pm 0,43 \mathrm{~g}$ e $0,21 \pm 0,06 \mathrm{~g}$, respectivamente. Para 0 enraizamento das estacas de eucalipto foram necessários 316,42 graus-dia acumulados.
\end{abstract}

Palavras-chave: silvicultura, soma térmica, casa de vegetação

\section{D etermination of thermal time for the development of eucalyptus seedlings during rooting phase}

\begin{abstract}
The genus Eucalyptus is important in commercial forest plantations due to its rapid grow th and ability to adapt to Brazilian climatic conditions. Among the most important stages for production of eucalyptus seedlings, through vegetative propagation, rooting is highlighted due to its requirements for water, nutrients and management which may compromise the quality of seedlings growing demand in Brazilian silviculture. This study aimed to determine the thermal sum to the rooting of clonal cuttings of eucalyptus (Eucalyptus grandis $x$ E. urophylla) and generate equations to estimate the biomass accumulation in the same stage of production, based on the concept of degree-days (thermal time). The study was conducted in an acclimatized greenhouse in the Seedling N ursery of the Department of Forestry, U niversidade Federal de Viçosa, Minas G erais State, Brazil. At the start of rooting, the mean fresh weight of seedlings was $0.76 \pm 0.17 \mathrm{~g}$ and the dry biomass was $0.17 \pm 0.04 \mathrm{~g}$. At the end of rooting, the means of fresh and dry biomass of seedlings were $1.49 \pm 0.43 \mathrm{~g}$ and $0.21 \pm 0.06 \mathrm{~g}$, respectively. For rooting of eucalyptus seedlings 316.42 degree-days were necessary.
\end{abstract}

Key words: forestry, thermal time, greenhouse

${ }^{1}$ DEA/U FV, Av. P. H. Rolfs, s/n, CEP 36570-000, Viçosa, MG. Fone: (31) 3899-1892. E-mail: aline.s.oliveira@ufv.br; ribeiro@ufv.br; yhasmin@gmail.com

2 U FSJ, Campus Sete Lagoas, Rodovia MG 424, km 47, CEP 35701-970, Sete Lagoas, MG. Fone: (31) 3697-2039. E-mail: antonio@ufsj.edu.br ${ }^{3}$ ICM Bio, Av. Tapajós, n 2201, Laguinho, CEP 68040-000, Santarém, PA. Fone: (91) 8139-6243. E-mail: nilton.rascon@icmbio.gov.br

${ }^{4}$ U FRPE, Fazenda Saco, s/n, Caixa Postal 063, CEP: 56.900-000, Serra Talhada, PE. Fone: (87) 3831-1927. E-mail: andreqa@gmail.com 


\section{INTRODUÇÃO}

O gênero Eucalyptus possui relevância em plantios florestais comerciais que visam à produção de celulose e papel, madeira e carvão, devido ao crescimento rápido e ser adaptado às condições climáticas do Brasil.

Para elevar a produtividade da cultura do eucalipto o processo de produção das mudas deve ser realizado propiciando condições hídricas, nutricionais e climáticas adequadas. Para isto, é importante o conhecimento da relação entre o desenvolvimento da planta na fase de muda e o ambiente (Gomes et al., 2002; Mantovani et al., 2003) aumentando a chance de sucesso na implantação da cultura.

Para garantir a homogeneidade e melhor qualidade das mudas, o desenvolvimento de florestas clonais de eucalipto tem sido cada vez mais utilizado, visto que permite a preservação dos genótipos de interesse e a manutenção da produtividade.

Dentre as fases de maior importância para a produção de mudas de eucalipto via propagação vegetativa, a de enraizamento se destaca caso as necessidades hídricas, nutricionais e climáticas não sejam atendidas, podendo comprometer a qualidade das mudas e, em consequência, a oferta de material na crescente demanda silvicultural brasileira.

Segundo Mafia et al. (2005) a má formação do sistema radicular impede a absorção de água e nutrientes em quantidades suficientes para atender às necessidades da planta resultando em um quadro sintomatológico típico de deficiência hídrica e/ou nutricional, em consequência do desequilíbrio entre raiz e parte aérea. Freitas et al. (2005) afirmam que mudas com problemas de deformação radicular no viveiro podem reduzir ou atrasar seu crescimento no campo, acarretando maiores custos na manutenção do povoamento.

Diversas variáveis influenciam no crescimento e desenvolvimento das raízes quando se usa propagação de plantas por meio de estacas, tais como: espécie, período de coleta das estacas, estado nutricional, sanidade, disponibilidade de água e variações nas condições climáticas (Higashi et al., 2000).

Dentre as variáveis climáticas que influenciam o crescimento e o desenvolvimento das plantas a temperatura é de relevância considerável para os processos fisiológicos, haja vista estar diretamente relacionada aos processos de evapotranspiração e às reações metabólicas existentes atuando também na duração do ciclo de desenvolvimento e na época da colheita; outro fator a se destacar é que a temperatura é uma variável de fácil medição, por existir diversos métodos para tal função, permitindo a utilização de sistemas robustos e de baixo custo.

Segundo Ometto (1981) existe um valor de energia mínima que aciona os mecanismos metabólicos das plantas, denominado temperatura base inferior, em que apenas estados energéticos acima deste limite são propícios ao crescimento e ao desenvolvimento dos vegetais. De acordo com Martins et al. (2007) a temperatura basal inferior para o desenvolvimento de mudas de Eucalyptus grandis é de $10{ }^{\circ} \mathrm{C}$ e a basal superior é de $36^{\circ} \mathrm{C}$ (Almeida et al., 2004; Dye et al., 2004).

Neste sentido e para que uma espécie vegetal atinja certo grau de desenvolvimento fenológico, é necessário que ocorra o acúmulo de determinada quantidade de energia, denominada graus-dia acumulados ou soma térmica, que representa o acúmulo térmico acima da temperatura base inferior. Segundo Taiz \& Zeiger (2004) as reações bioquímicas serão aceleradas caso não sejam mantidas dentro de uma faixa de temperatura adequada para o funcionamento das enzimas. Valores acima ou abaixo de determinada faixa de temperatura podem causar desnaturação das enzimas, provocando perdas da sua função biológica e, em contrapartida, na taxa de crescimento.

A determinação dos graus-dia acumulados possui grande importância para a avaliação da duração do ciclo fenológico das culturas uma vez que, considerando apenas o tempo cronológico, poderão ocorrer variações em função das condições meteorológicas existentes. Além disto, se apresenta como ferramenta relevante no processo de redução de riscos climáticos, pois o conhecimento das exigências térmicas de determinada cultura contribui para a definição antecipada do planejamento das atividades florestais e indicação do potencial climático da região visando à produção.

Diversos estudos têm associado o conceito de tempo térmico aos processos fisiológicos de várias culturas (Roberto et al., 2004; Paula et al., 2005; Stenzel et al., 2006; Pezzopane et al., 2008; Souza et al., 2009; Wagner et al., 2011). Contudo, na revisão realizada não foram encontradas pesquisas relativas à acumulação dos graus-dia para o enraizamento de mudas de eucalipto ou para qualquer espécie florestal.

Visando contribuir para o melhor entendimento dos fatores envolvidos na interação planta-ambiente, realizou-se a presente pesquisa com o objetivo de determinar a soma térmica para o enraizamento de estacas clonais de eucalipto (Eucalyptus grandis x E. urophylla) e gerar equações de estimativa para o acúmulo de biomassa na mesma fase de produção, com base no conceito de graus-dia.

\section{MATERIAL E MÉTODOS}

O experimento foi conduzido em uma casa de vegetação climatizada no período de 07/08/2009 a 09/09/2009, no viveiro de mudas de eucalipto do Departamento de Engenharia Florestal da Universidade Federal de Viçosa, Viçosa, Minas Gerais, cuja área experimental está localizada na latitude $20^{\circ} 45^{\prime} 45^{\prime \prime} \mathrm{S}$, longitude $42^{\circ} 52^{\prime} 04^{\prime \prime} \mathrm{W}$ e altitude de $690 \mathrm{~m}$. De acordo com a classificação de Köppen, o clima da região é do tipo temperado quente-mesotérmico ( $\mathrm{Cwa}$ ), com verões chuvosos e invernos secos; apresenta precipitação média anual de $1.220 \mathrm{~mm}$, temperatura máxima média de $26^{\circ} \mathrm{C}$ e mínima média de $14{ }^{\circ} \mathrm{C}$.

A casa de vegetação é revestida com filme plástico de polietileno de baixa densidade (PEBD) de $150 \mu \mathrm{m}$ e sombrite com malha de 50\%. A estrutura é de aço galvanizado, com dimensões de $7 \times 13 \mathrm{~m}$, pé direito lateral de $3 \mathrm{~m}$ e piso interno revestido de concreto.

A irrigação das mudas de eucalipto foi feita por meio de um sistema de nebulização formado por 176 bicos nebulizadores, espaçados a cada $50 \mathrm{~cm}$, com uma vazão unitária de $7 \mathrm{~L} \mathrm{~h}^{-1} \mathrm{e}$ pressão de serviço de 40 mca. O sistema de nebulização foi comandado por um controlador digital, conectado a um sensor de temperatura do tipo termistor e um sensor de umidade relativa do ar do tipo capacitivo. A irrigação foi acionada quando a 
temperatura do ar no interior da casa de vegetação ultrapassava $30{ }^{\circ} \mathrm{C}$ ou quando a umidade relativa do ar fosse inferior a $85 \%$.

As estacas de eucalipto foram obtidas do cruzamento entre as espécies Eucalyptus grandis e Eucalyptus urophylla, fornecidas pela Empresa Celulose Nipo-Brasileira S.A. (CENIBRA) localizada em Belo Oriente, Minas Gerais. O armazenamento das estacas após a coleta e para transporte foi realizado em caixas de isopor contendo vermiculita e bolsa térmica de gel frio, a fim de manter o vigor e a turgescência das brotações, garantindo o máximo potencial de enraizamento. Todas as estacas apresentavam características homogêneas com altura de aproximadamente $10 \mathrm{~cm}$ e dois pares de folhas com área foliar reduzida em $40 \%$ a fim de diminuir sua transpiração e tinham qualidade fitossanitária e fisiológica.

Os recipientes utilizados no estaqueamento das mudas de eucalipto foram tubetes de polipropileno com capacidade volumétrica de $55 \mathrm{~cm}^{3}$ e altura de $12,5 \mathrm{~cm}$. Os tubetes foram preenchidos com uma mistura de substrato comercial à base de casca de pinus compostada, fertilizante superfosfato simples (0-18-0) e fertilizante de liberação lenta (formulação 19-6-10). O enchimento dos tubetes foi realizado de forma mecanizada, empregando-se um equipamento que executava 22 batidas em cada bandeja de tubetes para o assentamento e acomodação do substrato.

Para o estaqueamento das mudas de eucalipto foram montadas 11 bandejas com capacidade unitária para 176 tubetes, sendo ocupadas somente 78 divisórias de cada bandeja a fim de evitar a sobreposição de folhas e minimizar a disseminação de doenças entre as estacas. As bandejas foram apoiadas em bancadas de concreto armado e superfície metálica, suspensas a uma altura de $90 \mathrm{~cm}$ do piso da casa de vegeração.

Com vista à determinação do acréscimo de biomassa das estacas de eucalipto em fase de enraizamento, optou-se por utilizar o método destrutivo no qual, a partir da data de estaqueamento, com periodicidade de três dias, eliminava-se uma bandeja para medir a biomassa fresca e seca de cada uma das estacas. Após a retirada de cada tubete o substrato de cultivo foi removido por imersão em água, de maneira a não causar danos às radículas das mudas. Posterior à medição da biomassa fresca, as estacas foram acondicionadas em sacos de papel e submetidas a secagem em estufa a $65^{\circ} \mathrm{C}$, até atingir massa constante. As medidas de biomassa fresca e seca foram realizadas em uma balança de precisão com resolução de $0,1 \mathrm{~g}$.

O tempo térmico foi determinado com base nas medidas de temperatura do ar de um sensor do tipo semicondutor com faixa de medição de $-55 \mathrm{a}+125^{\circ} \mathrm{C}$ e resolução de $0,1^{\circ} \mathrm{C}$, instalado no centro da casa de vegetação, próximo do topo do dossel vegetativo das estacas e conectado a um computador para armazenamento dos dados coletados, com média a cada 10 min. Para o cálculo dos graus-dia acumulados utilizou-se a metodologia proposta por Villa-Nova et al. (1972) (Eq. 1).

$$
\mathrm{GD}_{\text {acum }}=\sum_{\mathrm{i}=1}^{\mathrm{n}}\left[\left(\mathrm{T}_{\min }-\mathrm{T}_{\mathrm{i}}\right)+\frac{\left(\mathrm{T}_{\max }-\mathrm{T}_{\min }\right)}{2}\right]
$$

em que:

$\mathrm{GD}_{\text {acum }}$ - graus-dia acumulados, ${ }^{\circ} \mathrm{C}$ n - número de dias, adimensional

$\mathrm{T}_{\max }$ - temperatura do ar máxima diária no interior da casa de vegetação, ${ }^{\circ} \mathrm{C}$

$\mathrm{T}_{\min }$ - temperatura do ar mínima diária no interior da casa de vegetação, ${ }^{\circ} \mathrm{C}$

$\mathrm{T}_{\mathrm{i}}$ - temperatura basal inferior da cultura, $10^{\circ} \mathrm{C}$

Com base nas medições das biomassas e nas medições de temperatura do ar no interior da casa de vegetação foi possível obter equações associando a biomassa fresca, a biomassa seca e a acumulação da massa de água pelas estacas de eucalipto com os graus-dia acumulados, utilizando-se o programa computacional SigmaPlot (versão 10.0).

\section{Resultados E DisCUSSÃO}

No início do experimento a média de biomassa fresca das plantas foi de $0,76 \pm 0,17 \mathrm{~g}$ e após o enraizamento completo das estacas de eucalipto, a média de biomassa fresca foi de 1,49 \pm 0,43 g (Figura 1).

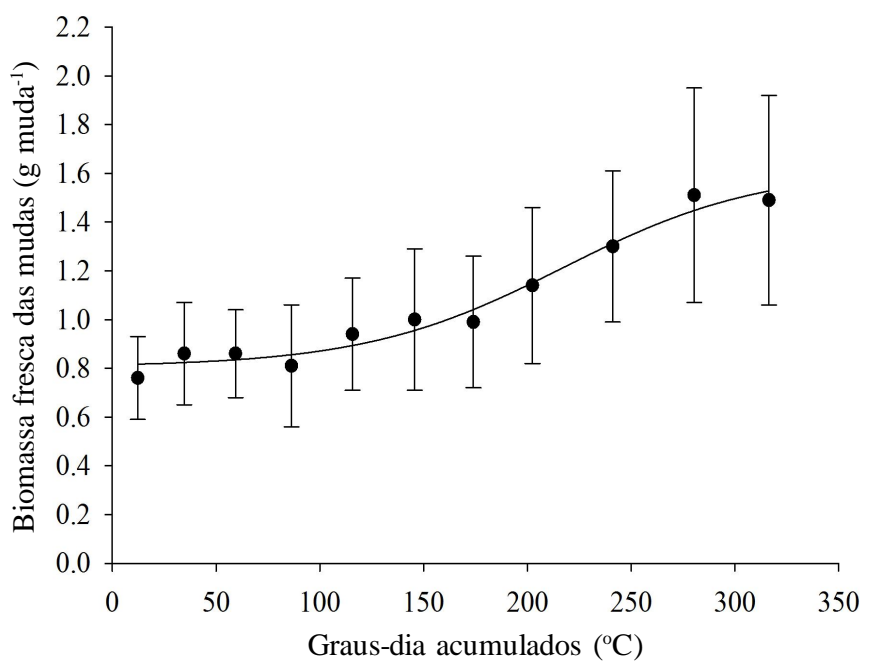

Figura 1. Variação da biomassa fresca média das mudas de eucalipto com os graus-dia acumulados

Durante o período experimental a temperatura média diária do ar no interior da casa de vegetação variou de 15,9 a $23,2{ }^{\circ} \mathrm{C}$ e momento algum a temperatura foi menor do que a temperatura basal inferior para o desenvolvimento do eucalipto.

De acordo com a Figura 1 é possível constatar que até os 86,36 graus-dia acumulados o processo de enraizamento apresentou crescimento lento devido, provavelmente, à ocorrência da formação endógena de primórdios radiculares. Hartmann et al. (2011) afirmam que a formação de raízes adventícias em estacas envolve a formação e a diferenciação de grupos de células meristemáticas em primórdios de raiz, incluindo a ruptura de outros tecidos do caule para formação de conexões vasculares com os tecidos condutores da estaca.

Segundo Xavier et al. (2009) o enraizamento em mudas produzidas por estaquia se constitui em um processo complexo que envolve o redirecionamento do desenvolvimento de células 
vegetais totipotentes para a formação de um meristema direcionado à formação de um novo sistema radicular.

Após o aparecimento das primeiras raízes e a formação de células especializadas na absorção de água e nutrientes pela muda, verificou-se aceleração do crescimento radicular e a emissão de raízes ficou evidente a partir de 115,71 graus-dia acumulados (Figura 1). O afloramento das raízes no fundo dos tubetes ocorreu após o acúmulo de 316,42 graus-dia.

A partir dos dados de biomassa fresca das mudas e dos graus-dia acumulados, medidos e armazenados no decorrer do experimento, foi possível gerar uma equação correlacionando ambas as variáveis e usando o modelo sigmoidal com 4 parâmetros (Eq. 2). O coeficiente de correlação do ajuste foi de 0,986. Conforme Kamkar et al. (2012), modelos de regressão não lineares têm sido muito utilizados para descrever a taxa de desenvolvimento de muitas culturas.

$$
\mathrm{BFM}=0,801+\frac{0,823}{1+\exp \left(\frac{\mathrm{GD}_{\text {acum }}-217,2589}{49,5510}\right)}
$$

em que:

BFM - biomassa fresca das mudas, g muda $^{-1}$

$\mathrm{GD}_{\text {acum }}$ - graus-dia acumulados, adimensional

Durante o enraizamento das estacas de eucalipto não foram observadas expansão de área foliar e emissão de novas folhas. Assim, o incremento de biomassa das estacas de eucalipto ocorreu em função do crescimento e do desenvolvimento do sistema radicular. Segundo Araújo et al. (2004) durante a fase de enraizamento a planta utiliza carboidratos armazenados na estaca como fonte de carbono para a síntese de substâncias essenciais à formação das raízes.

Com relação à biomassa seca das plantas, no início do enraizamento a média foi de $0,17 \pm 0,04 \mathrm{~g}$; ao final doexperimento a média de biomassa seca foi de $0,21 \pm 0,06 \mathrm{~g}$ (Figura 2).

Ao analisar a Figura 2 constata-se que, após o acúmulo de 86,36 graus-dia, a biomassa seca das mudas apresentou tendência de comportamento linear; além disto, o incremento na biomassa seca da fase de estaqueamento até o completo

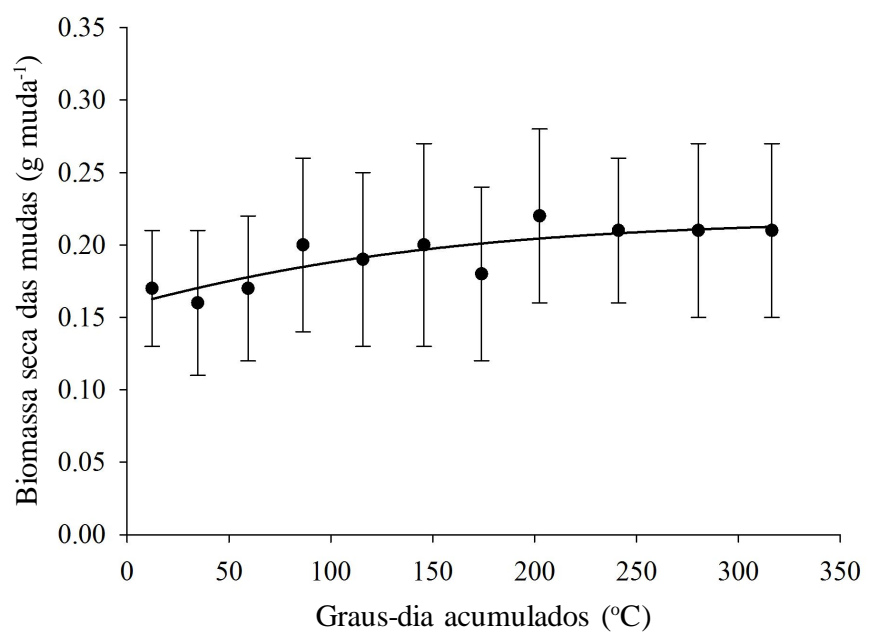

Figura 2. Variação da biomassa seca média das mudas de eucalipto com os graus-dia acumulados enraizamento foi de aproximadamente $21 \%$ indicando que, nesta fase de produção, o principal constituinte das estacas é a água.

Obteve-se a relação entre a biomassa seca das mudas e os graus-dia acumulados com base no modelo sigmoidal com 3 parâmetros (Eq. 3) atingindo coeficiente de correlação de 0,837 . Silva et al. (2009) também afirmaram, analisando o crescimento do girassol em função dos graus-dia acumulados, que o modelo sigmoidal com três parâmetros foi o que melhor se ajustou à variável massa seca total das plantas.

$$
\mathrm{BSM}=\frac{0,2121}{1+\exp \left(\frac{\mathrm{GD}_{\mathrm{acum}}+80,6753}{86,7713}\right)}
$$

em que:

BSM - biomassa seca das mudas, g muda $^{-1}$

$\mathrm{GD}_{\text {acum }}$ - graus-dia acumulados, adimensional

Comparando as Figuras 1 e 2 é possível concluir que, apesar da biomassa fresca das mudas ter apresentado crescimento mais acelerado após os 86,36 graus-dia acumulados, o mesmo não ocorreu com a biomassa seca visto que, a partir deste acúmulo de graus-dia, a massa permaneceu aproximadamente constante, em torno de $0,20 \mathrm{~g}$. Conforme já explicado, tal variação no comportamento entre as biomassas fresca e seca pode ter ocorrido em função do conteúdo de água na estaca, sendo menor o acúmulo no início e aumentando gradativamente no decorrer do período de enraizamento. Na Figura 3 consta a variação da massa de água, em g muda ${ }^{-1}$, à medida que ocorreu o acúmulo dos graus-dia.

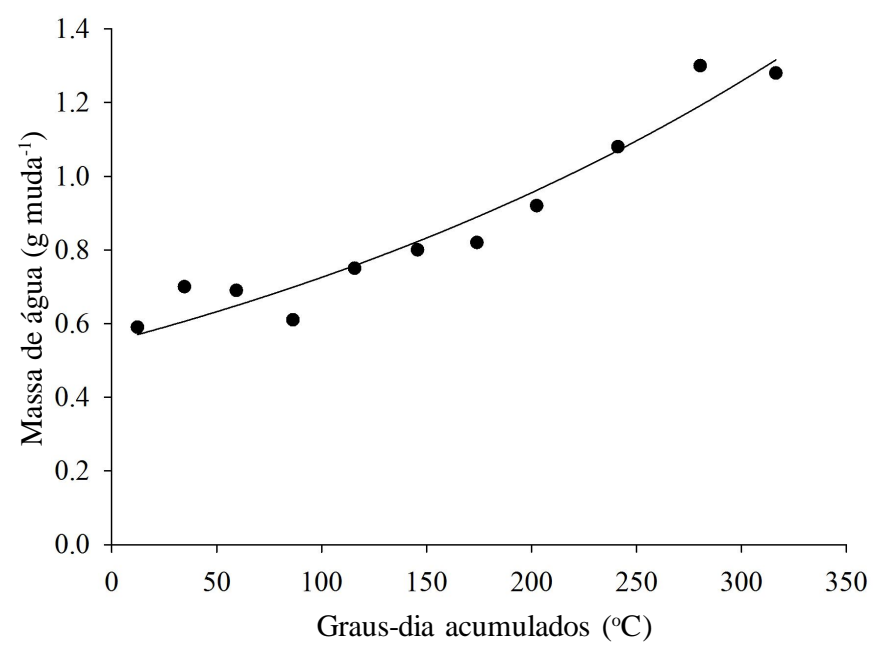

Figura 3. Variação da massa de água nas estacas de eucalipto em função dos graus-dia acumulados

É possível verificar, na Figura 3, que no início do período de enraizamento a massa de água ficou em torno de $0,65 \mathrm{~g} \mathrm{muda}^{-1}$, correspondendo a 77,92\% de água na planta. Após 86,36 grausdia acumulados a massa de água apresentou um acúmulo maior resultando, no final do enraizamento, em um conteúdo de água na planta de $86,18 \%$, o que representa $1,28 \mathrm{~g}$ muda $^{-1}$. Por meio de um modelo exponencial com 2 parâmetros obteve-se um bom ajuste entre essas variáveis, apresentando coeficiente de correlação de 0,967 (Eq. 4). 


$$
\mathrm{MA}=0,551 \exp ^{\left(0,003 \mathrm{GD}_{\text {acum }}\right)}
$$

em que:

MA - massa de água, g muda ${ }^{-1}$

$\mathrm{GD}_{\text {acum }}$ - graus-dia acumulados, adimensional

O ajuste de modelos que correlacionam variáveis associadas à interação planta-ambiente no enraizamento de diferentes materiais genéticos a serem propagados no viveiro, pode minimizar os custos em virtude da otimização da utilização das instalações e redução das perdas ocasionadas por doenças uma vez que não será conveniente a permanência dos propágulos sob condições favoráveis à incidência de doenças por tempo além daquele requerido para iniciar o processo rizogênico (Ferreira et al., 2004).

Para o enraizamento das estacas clonais de eucalipto foram necessários 316,42 graus-dia acumulados, o que correspondeu a aproximadamente 30 dias. Em estudos nos quais se avalia a velocidade de enraizamento de diferentes clones de eucalipto (E. grandis $\mathrm{x}$ E. urophyilla e E. grandis x E. saligna) considerando o tempo cronológico, pode-se citar a pesquisa de Ferreira et al. (2004) que encontraram valores de 20 e 30 dias para o enraizamento de dois diferentes materiais genéticos $(E$. grandisx E. urophylla e E. grandisx E. saligna).

Considerando a otimização das instalações do viveiro, os resultados obtidos nesta pesquisa permitem inferir que a soma de graus-dia possibilita determinar a duração do período de enraizamento. Infeld et al. (1998) afirmam que o uso do tempo térmico para determinação da duração fenológica das culturas fornece maior segurança e exatidão comparativamente à simples contagem do número de dias. Este conceito é importante uma vez que considera as variações climáticas que ocorrem durante o ano e, portanto, independe da região na qual as mudas de eucalipto serão produzidas.

\section{CONCLUSÕES}

1. Para o enraizamento completo das mudas de eucalipto $(E$. grandis x E. urophylla), foram necessários 316,42 graus-dia acumulados.

2. As equações geradas para estimativa do acúmulo de biomassa com base no tempo térmico foram satisfatórias, apresentando alto coeficiente de correlação.

\section{LITERATURA CITADA}

Almeida, A. C.; Landsberg, J. J.; Sands, P. J. Parameterisation of 3-PG model for fast-growing Eucalyptus grandis plantations. Forest Ecology and Management, v.193, p.179195, 2004.

Araújo, J. P. C.; Scarpare Filho, J. A.; Rodrigues, A. 2004. Alporquia em lichia: Épocas e concentrações de carboidratos solúveis em ramos. In: Congresso Brasileiro de Fruticultura, 18, 2004, Florianópolis, Anais... Florianópolis: Adaltech. 2004. CD-Rom
Dye, P. J.; Jacobs, S.; Drew, D. Verification of 3-PG growth and water-use predictions in twelveEucalyptus plantation stands in Zululand, South Africa. Forest Ecology and Management, v.193, p.197-218, 2004.

Ferreira, E. M.; Alfenas, A. C.; Mafia, R. G.; Leite, H. G; Sartorio, R. C.; Penchel Filho, R. M. Determinação do tempo ótimo do enraizamento de miniestacas de clones de Eucalyptus spp. Revista Árvore, v.28, p.183-187, 2004.

Freitas, T. A. S.; Barroso, D. G.; Carneiro, J. G. A.; Penchel Filho, R. M.;Lamônica, K. R.; Ferreira, D. A. Desempenhoradicular de mudas de eucalipto produzidas emdiferentes recipientes e substratos. Revista Árvore, v.29, p.853-861, 2005.

Gomes, J. M.; Couto, L.; Leite, H. G.; Xavier, A.; Garcia, S. L. R. Parâmetros morfofisiológicos na avaliação da qualidade de mudas de Eucalyptus grandis. Revista Ârvore, v.26, p.655664, 2002.

Hartmann, H. T.; Kester, D. E.; Davies Júnior, F. T.; Geneve, R. L. Plant propagation - principles and practices. 8.ed. New York: Prentice-Hall International, 2011. 915p.

Higashi, E. N.; Silveira, R. L. V. A.; Gonçalves, A. N. Propagação vegetativa de Eucalyptus: Princípios básicos e a sua evolução no Brasil. São Paulo: Instituto de Pesquisas e Estudos Florestais, 2000.14p. Circular Técnica, 192

Infeld, J. A.; Silva, J. B.; Assis, F. N. Temperatura-base e grausdias durante o período vegetativo de três grupos de cultivares em arroz irrigado. Revista Brasileira de Agrometeorologia, v.6, p.49-53, 1998.

Kamkar, B.; Al-Alahmadi, M. J.; Mahdavi-Damghani, A.; Villalobos, F. J. Quantification of the cardinal temperatures and thermal time requirement of opium poppy (Papaver somniferum L.) seeds to germinate using non-linear regression models. Industrial Crops and Products, v.35, p.192-198, 2012.

Mafia, R. G.; Alfenas, A. C.; Siqueira, L.; Ferreira, E. M.; Leite, H. G.; Cavallazzi, J. R. P. Critério técnico para determinação da idade ótima de mudas de eucalipto para plantio. Revista Árvore, v.29, p.947-953, 2005.

Mantovani, M.; Ruschel, A. R.; Reis, M. S.; Puchalski, A.; Nodari, R. O. Fenologias reprodutivas de espécies arbóreas em uma formação secundária da Floresta Atlântica. Revista Árvore, v.27, p.451-458, 2003.

Martins, F. B. Silva, J. C.; Streck, N. A. Estimativa da temperatura-base para emissão de folhas e do filocrono em duas espécies de eucalipto na fase de muda. Revista Árvore, v.31, p.373-381, 2007.

Ometto, J. C. Bioclimatologia vegetal. 1.ed. São Paulo: Agronômica Ceres, 1981.440p.

Paula, F. L. M.; Streck, N. A.; Heldwein, A. B.; Bisognin, D. A.; Paula, A. L.; Dellai, J. Soma térmica de algumas fases do ciclo de desenvolvimento da batata (Solanum tuberosum L.). Ciência Rural, v.35, p.1034-1042, 2005.

Pezzopane, J. R. M.; Pedro Júnior, M. J.; Camargo, M. B. P.; Fazuoli, L. C. Exigência térmica do café arábica cv. Mundo Novo no subperíodo florescimento-colheita. Ciência e Agrotecnologia, v.32, p.1781-1786, 2008.

Roberto, S. R.; Sato, A. J.; Brenner, E. A.; Santos, C. E.;Genta, W. Fenologia e soma térmica (graus-dia) para a videira 'Isabel' (Vitis labrusca) cultivada no Noroeste do Paraná. Semina: Ciências Agrárias, v.25, p.273-280, 2004. 
Silva, T. G. F.; Zolnier, S.; Grossi, J. A. S.; Barbosa, J. G.; Moura, C. R. W.; Muniz, M. A. Crescimento do girassol ornamental cultivado em ambiente protegido sob diferentes níveis de condutividade elétrica de fertirrigação. Revista Ceres, v.56, p.602-610, 2009.

Souza, A. P.; Silva, A. C.; Leonel, S.; Escobedo, J. F. Temperaturas basais e soma térmica para a figueira podada em diferentes épocas. Revista Brasileira de Fruticultura, v.31, p.314-322, 2009.

Stenzel, N. M. C.; Neves, C. S. V. J.; Marur, C. J.; Scholz, M. B. S.; Gomes, J. C. Maturation curves and degree-days accumulation for fruits of 'folha murcha' orange trees. Scientia Agricola, v.63, p.219-225, 2006.
Taiz, L.; Zeiger, E. Fisiologia vegetal. 3.ed. Porto Alegre: Artmed, 2004.719p.

Villa-Nova, N. A.; Pedro Júnior, M. S.; Pereira, A. R.; Ometto, J. C. Estimativa de graus dia acumulados acima de qualquer temperatura base, em função das temperaturas máxima e mínima. São Paulo: Instituto de Geografia/USP, 1972. 8p. Caderno de Ciência da Terra, n.30.

Wagner, M. V.; Jadoski, S. O.; Lima, A. S.; Maggi, M. F.; Pott, C. A.; Suchoronczec, A.Avaliação do ciclo fenológico da cultura do milho em função da soma térmica em Guara-puava, Sul do Brasil. Pesquisa Aplicada \& Agrotecnologia, v.4, 2011. Xavier, A.; Wendling, I.; Silva, R.L.Silvicultura clonal: Princípios e técnicas. Viçosa: Editora UFV, 2009. 272p. 